\title{
Human Cytomegalovirus-Encoded miR-US25-1 Aggravates the Oxidised Low Density Lipoprotein-Induced Apoptosis of Endothelial Cells
}

\author{
Jianmin Fan, ${ }^{1}$ Wen Zhang, ${ }^{1}$ and Qiming Liu' ${ }^{2}$ \\ ${ }^{1}$ The First Affiliated Hospital of Hunan University of Traditional Chinese Medicine, Changsha 410007, China \\ ${ }^{2}$ Cardiovascular Medicine Department, The Second Xiangya Hospital of Central South University, Changsha 410011, China \\ Correspondence should be addressed to Qiming Liu; qim_liu@163.com
}

Received 18 February 2014; Revised 6 April 2014; Accepted 8 April 2014; Published 8 May 2014

Academic Editor: Paul Evans

Copyright (C) 2014 Jianmin Fan et al. This is an open access article distributed under the Creative Commons Attribution License, which permits unrestricted use, distribution, and reproduction in any medium, provided the original work is properly cited.

\begin{abstract}
Human cytomegalovirus (HCMV) infection is linked to the development and severity of the cardiovascular disease atherosclerosis; however, there is little known about the promotion of atherosclerosis. miR-US25-1 is one of HCMV-encoded miRNAs and targets cellular genes that are essential for virus growth to control the life cycle of the virus and host cells. The prominent regulation on cell cycle genes of the miR-US25-1 attracts us to explore its role in the atherosclerosis promotion. It was indicated that miRUS25-1 level was upregulated in subjects or in endothelial cells with HCMV infection; and the miR-US25-1 downregulated the expression of BRCC 3 by targeting the $5^{\prime}$ UTR of BRCC 3 . And a miR-US25-1 mimics transfection could reduce the EAhy 926 cell viability but did not induce apoptosis in EAhy926 cells. And what is more, miR-US25-1 mimicis transfection deteriorated the ox-LDL-induced apoptosis and aggravated the upregulation of apoptosis-associated molecules by oxidised low density lipoprotein (ox-LDL) in EAhy926 cells. And we have also confirmed the deregulation of BRCC 3 expression by miR-US25-1 by targeting the $5^{\prime}$ UTR of it. Given the vital role of BRCC 3 in DNA damage repairing, we speculated that the targeting inhibition of BRCC 3 by miR-US25-1 may contribute to the aggravation of ox-LDL-promoted apoptosis of endothelial EAhy926 cells.
\end{abstract}

\section{Introduction}

It is well known that the oxidized low density lipoprotein (oxLDL) plays a key role in the development of atherosclerosis [1]. And multiple types of cells, such as endothelial cells, macrophages, and smooth muscle cells, are involved in the ox-LDL-promoted atherosclerosis [2]. Ox-LDL is considered to induce apoptosis, monocyte adhesion, and reactive oxygen species generation [3-5] via upregulating [4] and binding to the lectin-like endothelial ox-LDL receptor (LOX-1) [4, $6]$ on the vascular endothelial cells. And various molecules play roles in the ox-LDL-induced apoptotic cascade, such as caspases [6], AIF [7], VPO1 [8], PKC, PTK, bcl-2, and Fas [9]. However, other studies show converse results. Prior exposure to ox-LDL limits apoptosis in subsequent generations of endothelial cells by altering promoter methylation [10].

The sustained high level of ox-LDL will finally lead to atherosclerosis. And what is more, there is a key role in the atherosclerosis acceleration by infection and inflammation [11-14]. The inflammation in vascular system is caused by vessel wall injury and endothelial cell (EC) dysfunction [15, 16] and is triggered by infectious agents such as human cytomegalovirus (HCMV) [17, 18]. Then, the following monocyte activation and cytokine and chemokine overproduction promote and accelerate the atherosclerotic plaque formation, endothelial and smooth muscle cell proliferation, atherosclerotic plaque rupture, and thrombus formation [1923]. HCMV infection is linked to the development and severity of the cardiovascular disease atherosclerosis [24]. HCMV has clearly been shown to be associated with an enhanced rate of restenosis and vasculopathy $[25,26]$. Additionally, serological studies indicate a link between HCMV and atherosclerosis $[27,28]$. Most knowledge about the molecular and cellular bases for the pathogenic effects of HCMV is based on its influence on the pattern of host cell gene expression $[17,29]$. Different molecules have been 
identified to be mediating the HCMV-induced changes of the cellular response including cytokines [30] and growth factors [31]. Up to now, it is not clear whether structural or no structural molecules expressed by HCMV are directly involved in the promotion of atherosclerosis.

MicroRNAs (miRNAs) are endogenous, noncoding RNA molecules of 18-22 nt that can bind the $3^{\prime}$-untranslated region of target messenger RNA (mRNA) and regulate gene expression in a broad array of cell processes in mammals [32-35]. And the regulation of miRNAs in the cardiovascular system has also been well confirmed [36-38]. Herpesviruses belong to a large family of enveloped, double-stranded DNA viruses that are able to maintain a persistent or latent infection during the lifetime of the virus in its host. Belonging to one of the three groups of herpesvirus, HCMV has been shown to encode miRNAs, indicating that HCMV has utilized the RNA interference machinery throughout their evolution [39]. HCMV miRNAs are spread throughout the viral genome and have been demonstrated to be expressed during acute lytic infection [40-43]. miR-US25-1 is one of HCMV-encoded miRNAs and targets cellular genes that are essential for virus growth to control the life cycle of the virus [44]. More recently, it is shown that the viral miR-US25-1 downregulates multiple cell cycle genes through mRNA $5^{\prime}$ UTRs [45]. The prominent regulation of cell cycle genes of the miR-US25-1 attracts us to explore its role in the atherosclerosis promotion.

The present study revealed that human cytomegalovirusencoded miR-US25-1 aggravates the ox-LDL-induced apoptosis of endothelial cells via targeting and downregulating BRCC 3.

\section{Results}

2.1. Upregulation of miR-US25-1 Level in Subjects or in Endothelial Cells with HCMV Infection. miR-US25-1 has been well confirmed to be encoded by HCMV to control the life cycle of the virus [44]; we detected the miR-US251 level (U6, the most highly conserved small nuclear RNA across species [46], as internal control) in whole blood samples of normal subjects with or without HCMV positive. It was indicated that there was a significant upregulation of the miR-US25-1 in whole blood of HCMV associated subjects $(2.72 \pm 1.13$ versus $1.00 \pm 0.35$ in $\mathrm{HCMV}$-negative subjects, $P=0.0013$ ) (Figure 1(a)). A significant upregulation of blood miR-US25-1 level was also confirmed in the atherosclerosis subjects with HCMV positive. As show in Figure 1(b), the average value of miR-US25-1 level in HCMVinfected atherosclerosis subjects was $2.31 \pm 0.71$, significantly higher than $1.00 \pm 0.42$ in the HCMV-negative atherosclerosis subjects $(P=0.0036)$. To further confirm the association of miR-US25-1 level with the active HCMV infection, the correlation between miR-US25-1 expression and the mRNA level of pp65, one of HCMV tegument proteins in the atherosclerosis patients, was explored. Figure 1(c) indicated a significant correlation of miR-US25-1 level with the pp65 mRNA level $\left(R^{2}=0.6543, P<0.0001\right)$.

To evaluate the miR-US25-1 expression in endothelial cells after HCMV infection, we determined the growth curve of the virus in EAhy926 cells with a control of virus growth curve in HEF cells. It was shown that HCMV replicated well in EAhy926 cells, the virus titer elevated to 5.33 ( $\mathrm{Lg}$ $(\mathrm{PFU} / \mathrm{mL}))$ at eight days after inoculation, with a similar growth curve in HEF cells, though significantly less than the titer in HEF cells (Figures 1(d) and 1(e)). And then the miRUS25-1 expression in EAhy926 cells was also determined; Figure 1(f) demonstrated a significant high miR-US25-1 level in EAhy926 cells from 2 to 8 D.P.I. compared with that in 0 D.P.I. $(P<0.05$ in 2 D.P.I. and $P<0.01$ in 4 , 6 , or 8 D.P.I., resp.). Taken together, the in vivo and in vitro results confirmed the upregulation by HCMV infection.

\section{2. miR-US25-1 Reduces Cell Viability but Does Not Induce} Apoptosis in EAhy926 Cells. To explore the influence of the miR-US25-1 expression on EAhy926 cells, we determined the viability and apoptosis of EAhy926 cells after HCMV infection or miR-US25-1 mimics transfection. The miRUS25-1 mimics significantly promoted the miR-US25-1 level in cells, with a $P$ value less than 0.0001 (Figure 2(a)). Firstly, to observe the influence of HCMV infection or miR-US251 transfection on the EAhy926 cells viability, the MTT assay was conducted. It was shown in Figure 2(b) that the HCMV infection with a MOI of 1 caused about $30 \%$ more cell viability decreasing from 4 to 8 D.P.I. $(P<0.05$ or $P<0.01)$. And $0.1 \mathrm{MOI}$ infection caused approximately $30 \%$ cell viability decreasing at 6 or 8 D.P.I. $(P<0.05$, either $)$. And the miRNA mimics transfection also significantly reduced the cell viability with a reduction of $20 \%$ at 24 H.P.T. or of $25 \%$ at 48 H.P.T. ( $P<0.05$, either). To further explore the mechanism of cell viability reduction by miR-US25-1, then, we determined the EAhy926 cell apoptosis after miRUS25-1 mimics transfection. Strikingly, Figures 2(d) and 2(e) demonstrated that there was no significant difference in apoptosis promotion between the miR-US25-1 mimics and miRNA control $(P>0.05)$. And there was also no significant difference in the caspase 3 activity between the miR-US251 mimics and miRNA control transfected EAhy926 cells (Figure 2(f)), reconfirming nonpromotion of miR-US25-1 to EAhy926 cell apoptosis.

2.3. miR-US25-1 Downregulates the Expression of BRCC 3 by Targeting the $5^{\prime}$ UTR of BRCC 3 . Unlike miRNAs encoded by eukaryotic cells, the HCMV-encoded miR-US25-1 was reported to primarily bind sites within the $5^{\prime}$ UTR of targeted genes and mediate the reduction in gene expression in HEK293 cells [45]. And many of the genes targeted by miRUS25-1 are associated with cell cycle control, including cyclin E2 and BRCC3 [45]. To investigate whether there is an association of miR-US25-1-targeted genes with the confirmed viability reduction in EAhy926 cells by miR-US25-1, we determined the expression of BRCC 3, which is one of most regulated molecules by miR-US25-1 and plays a vital role in DNA damage repairing [47] and in mRNA and protein levels in the EAhy926 cells after miR-US25-1 transfection. As shown in Figure 3(a), the miR-US25-1 mimics ( $50 \mathrm{nM})$ caused a 50$70 \%$ reduction of BRCC 3 mRNA $24-72 \mathrm{~h}$ after transfection, compared to the control group $(P<0.05$ at 24 or $72 \mathrm{~h}$, 


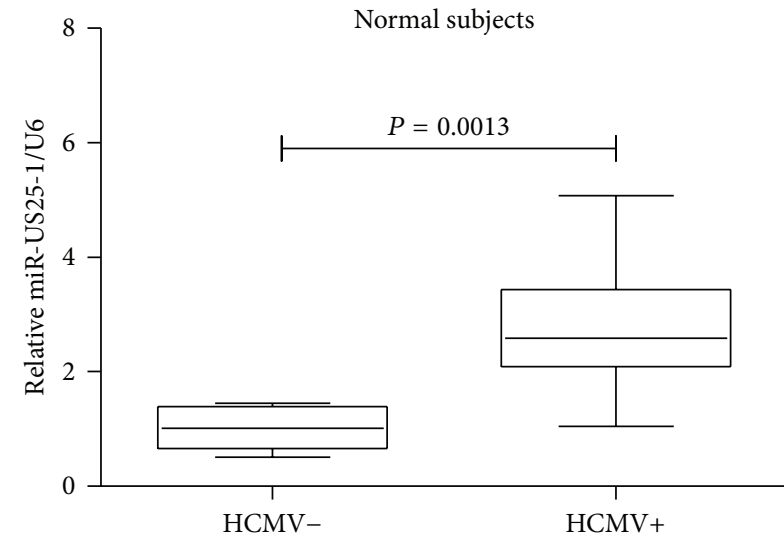

(a)

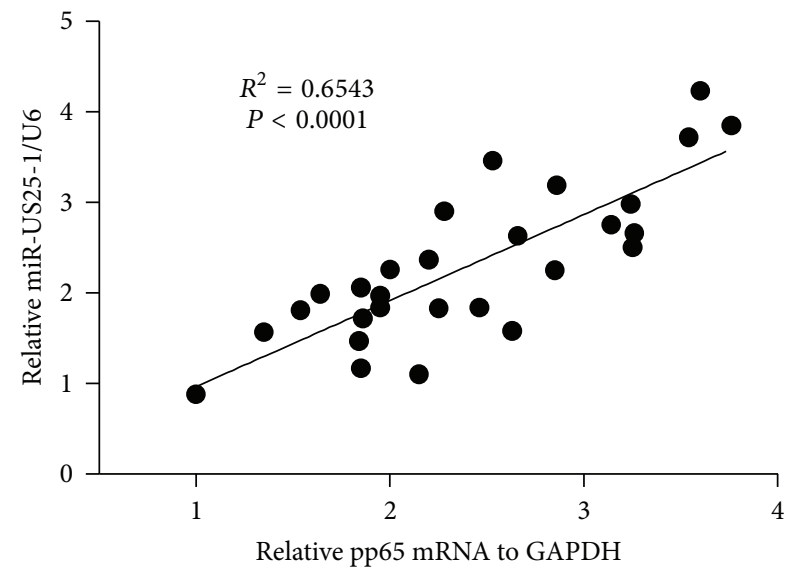

(c)

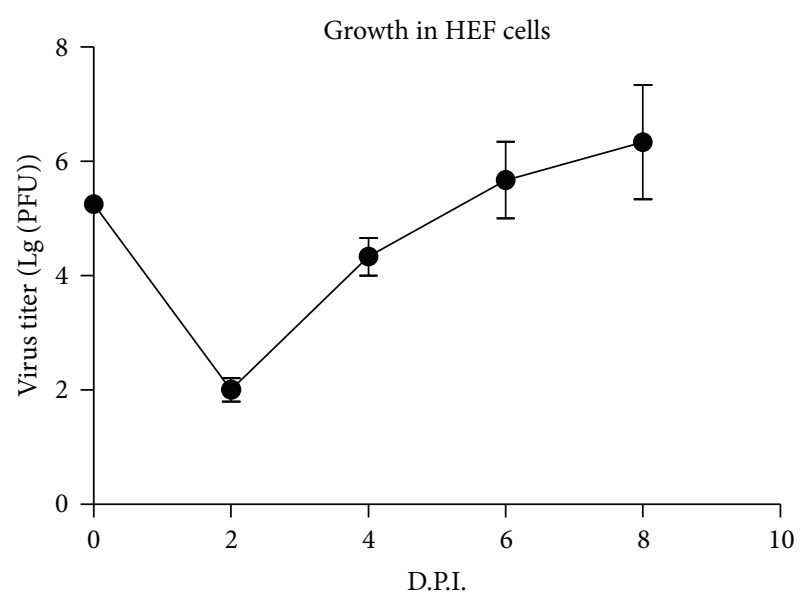

(e)

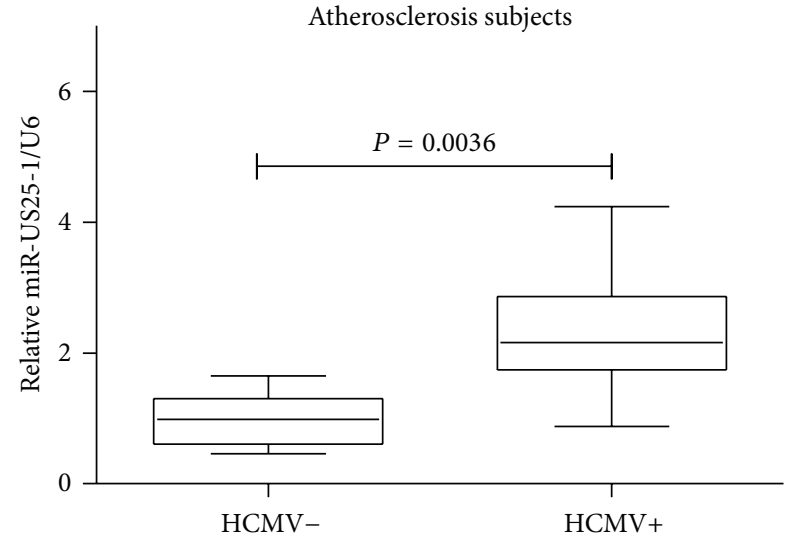

(b)

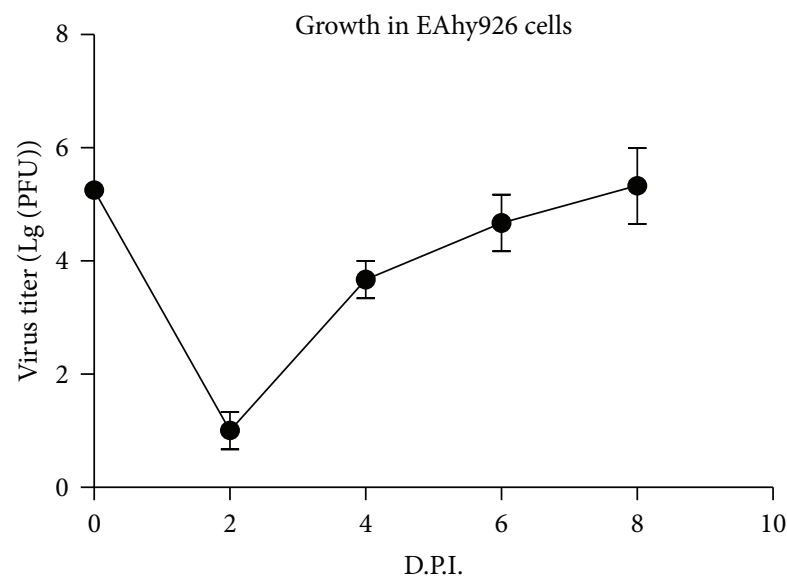

- - HCMV

(d)

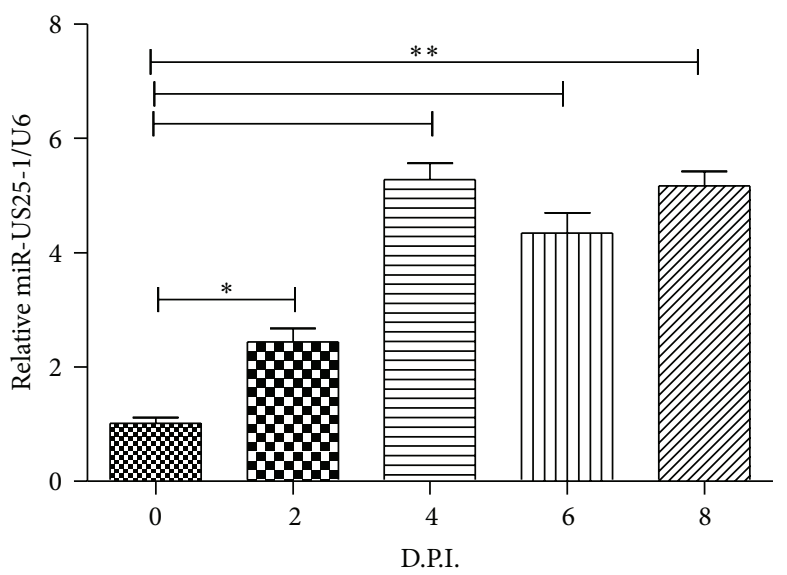

(f)

FIGURE 1: HCMV infection promoted miR-US25-1 level in vivo or in vitro. (a) The expression of miR-US25-1 was examined in blood samples of normal subjects with $(n=28)$ or without $(n=10)$ HCMV positive. (b) The expression of miR-US25-1 was examined in blood samples of atherosclerosis subjects with $(n=32)$ or without $(n=12)$ HCMV positive. (c) Correlation of miR-US25-1 expression with plasma pp65 mRNA level. (d) and (e) Growth curve of HCMV in EAhy926 or HEF cells, MOI = 0.1. (f) HCMV infection upregulates miR-US25-1 level in EAhy926 cells. All experiments for (d)-(f) were performed in triplicate independently. Statistical significance was showed as ${ }^{*} P<0.05$ and ${ }^{* *} P<0.01$. 

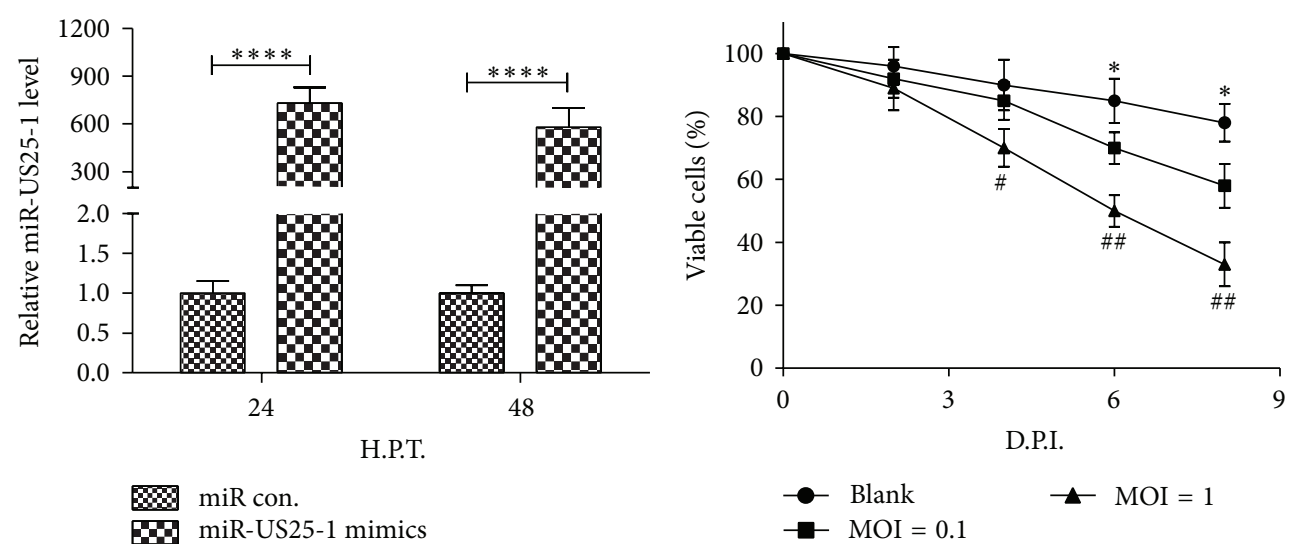

(a)

(b)

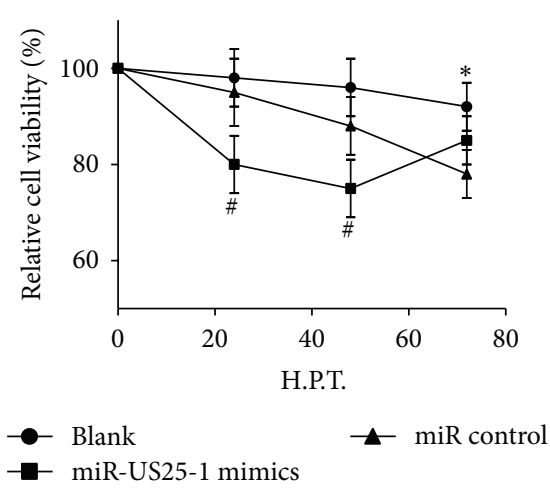

(c)
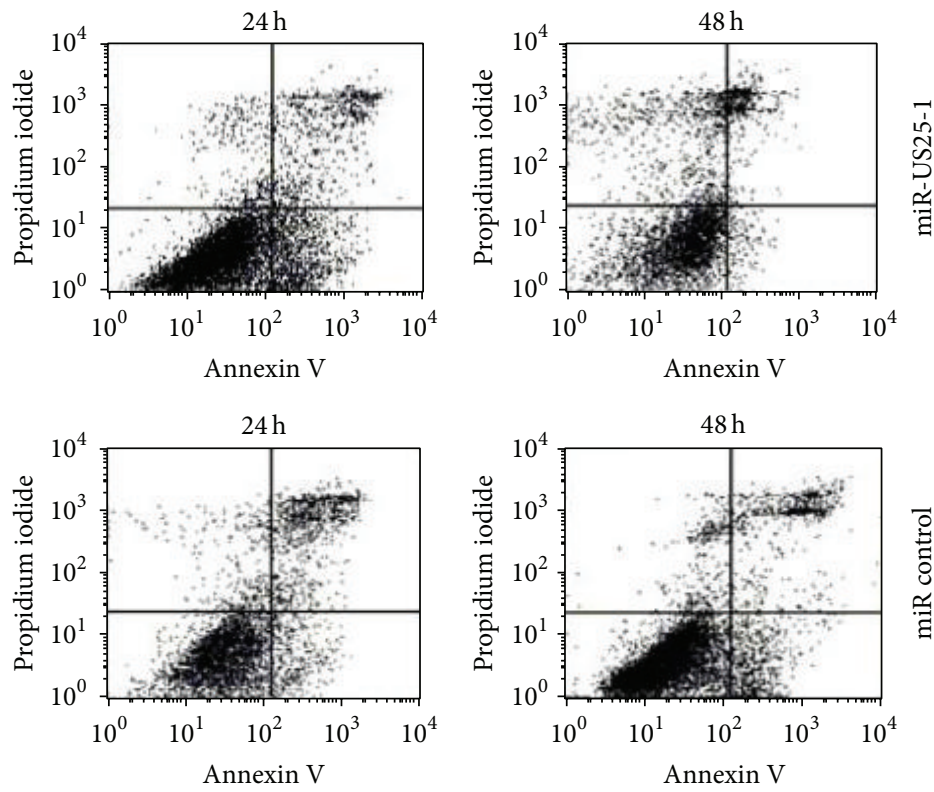

(e)

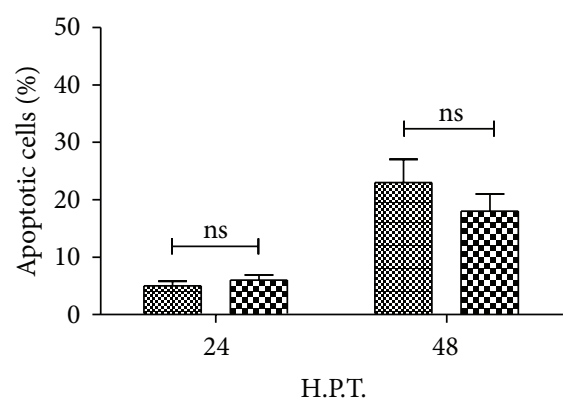

\$2 miR-US25-1 mimics De miR control

(d)

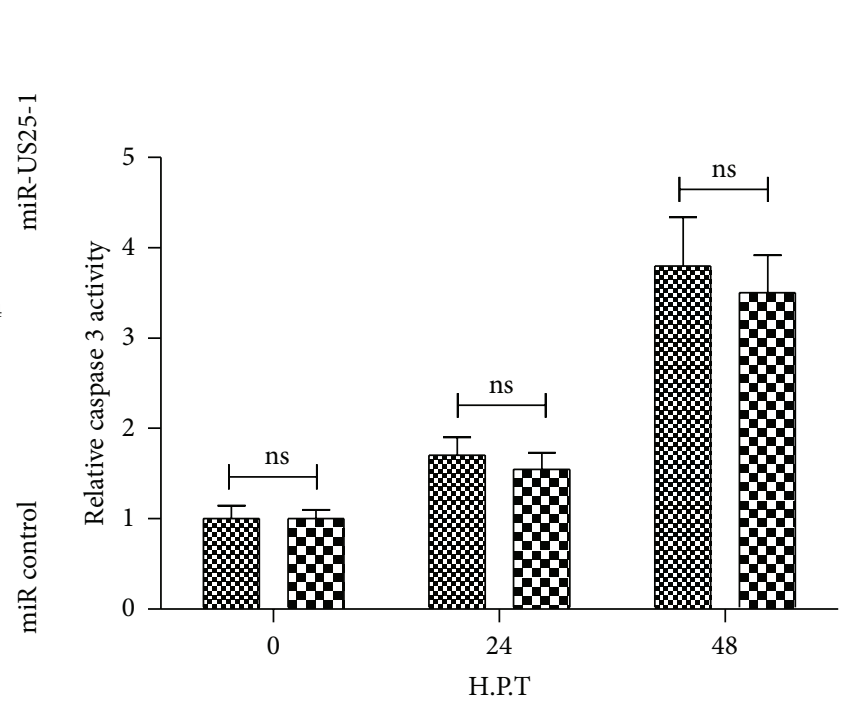

\% miR-US25-1 mimics miR control

(f)

FIgURE 2: miR-US25-1 mimics reduced EAhy926 cell viability but did not induce apoptosis in EAhy926 cells. (a) The miR-US25-1 level was promoted by miR-US25-1 mimics, rather than miR control, both of which were transfected in EAhy 926 cells with $50 \mathrm{nM}$. (b) Viability of EAhy926 cells decreased after HCMV infection with 0.1 or 1 MOI (compared to blank), revealed by MTT assay. (c) miR-US25-1 mimics, rather than miRNA control, reduced EAhy926 cell viability, revealed by MTT assay. (d) No significant difference in regulation of apoptosis of EAhy 926 cells by the miR-US25-1 mimics and the miRNA control. The results are expressed as percentages of positive mean values \pm S.E. for three independent experiments. (e) Apoptosis of EAhy926 cells with miR-US25-1 mimics or miRNA control transfection of $50 \mathrm{nM}$. (f) No significant difference in caspase 3 activity in EAhy926 cells after miR-US25-1 mimics or miRNA control transfection. ns: no significance, ${ }^{\#}$ or ${ }^{*} P<0.05,{ }^{\# \#} P<0.01$, and ${ }^{* * * *} P<0.0001$. 


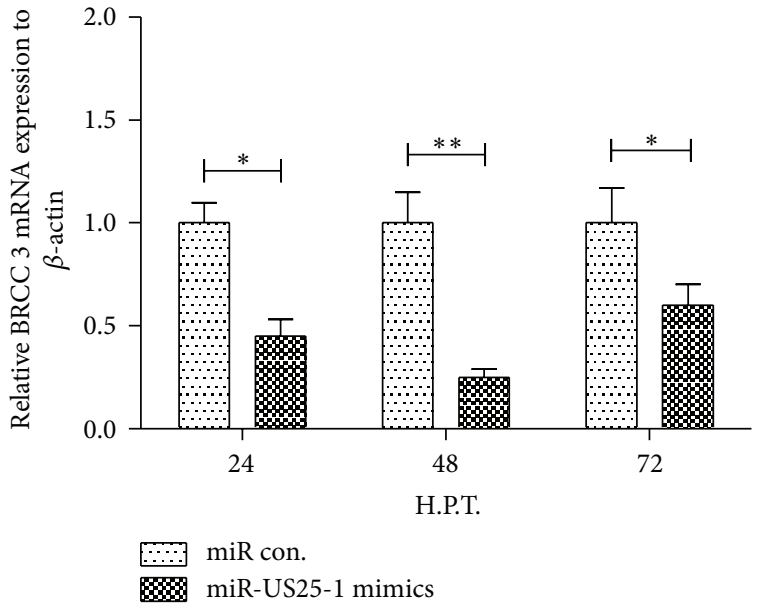

(a)

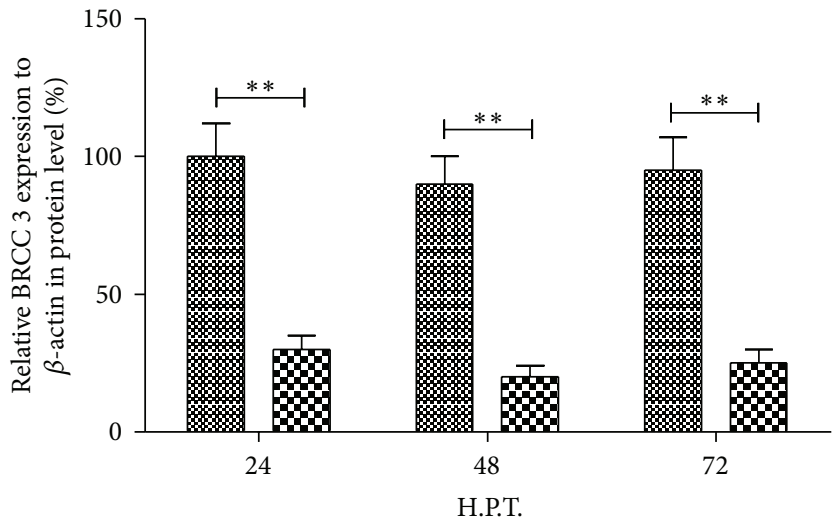

\% miR con.

Q0. miR-US25-1 mimics

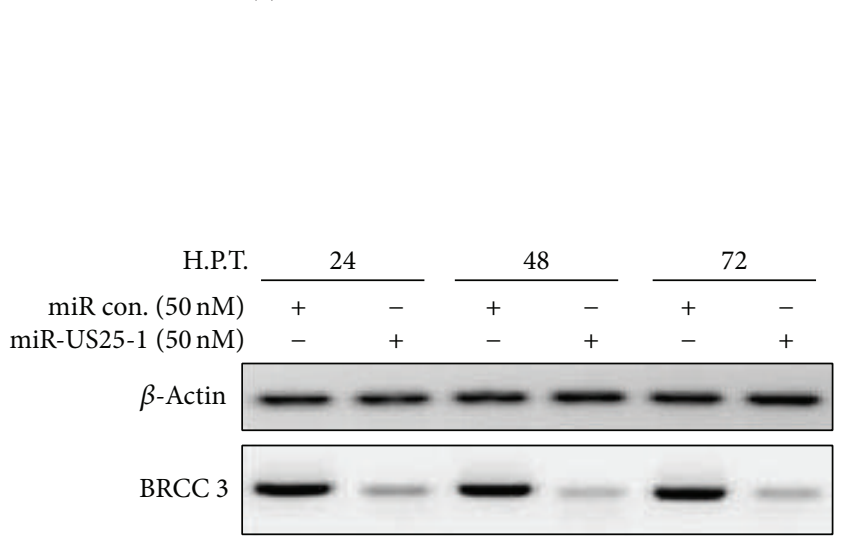

(c)

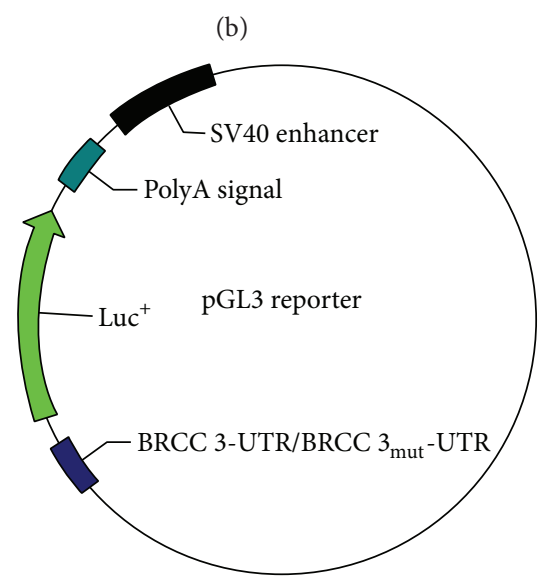

(d)

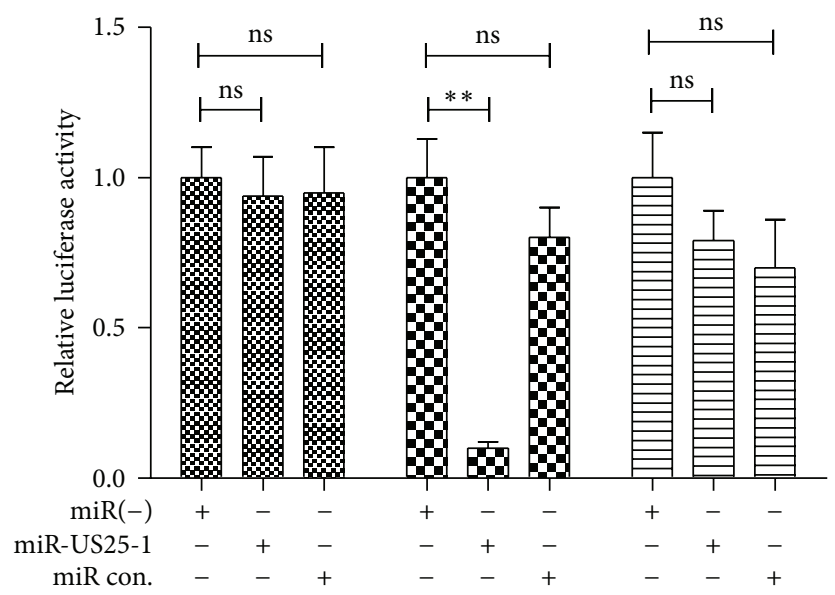

叉p pGL3 con.

PGL3-BRCC 3-UTR

E pGL3-BRCC $3_{\text {mut }}$-UTR

(e)

FIGURE 3: miR-US25-1 downregulated BRCC 3 by targeting the $5^{\prime}$ UTR. (a) BRCC 3 mRNA was reduced in EAhy926 cells after transfection with miR-US25-1 mimics. (b) and (c) Western blot analysis indicated that the expression of BRCC 3 was inhibited in protein level in EAhy926 cells by miR-US25-1 mimics transfection. (d) Schematic diagram of the pGL3-BRCC 3/BRCC $3_{\text {mut }}$ reporter construction. (e) Relative luciferase activity of pGL3-BRCC 3/BRCC $3_{\text {mut }}$ reporter or pGL-con vector in EAhy926 cells transfected with miR-US25-1 mimics. All experiments were performed in triplicate independently. Statistical significance was showed as ${ }^{*} P<0.05$ and ${ }^{* *} P<0.01$, ns: no significance. 
$P<0.01$ at $48 \mathrm{~h})$. The western analysis also revealed a significant BRCC 3 reduction (60-80\%) in protein level by the miRNA transfection with $50 \mathrm{nM}(P<0.05$ at 24 and $P<0.01$ at $48 \mathrm{~h}$ or $72 \mathrm{~h}$ ). To reconfirm the BRCC 3 downregulation by miR-US25-1, we construct a luciferase reporter constructs containing the miR-US25-1 recognizing 5 ' UTR sequences of BRCC 3 (Figure 3(d)). As shown in Figure 3(e), $50 \mathrm{nM}$ miRUS25-1 mimics suppressed while the miRNA control did not regulate the activity of pGL3-BRCC 3 reporter in EAhy926 cells $(P<0.01)$; and the miR-US25-1 mimics had no such suppression on the luciferase activity of pGL3-BRCC $3_{\text {mut }}$ or pGL3-con reporter. These results agree with the fact that miRUS25- 1 regulates BRCC 3 by targeting the $5^{\prime}$ UTR of it and suppressing its translation.

2.4. miR-US25-1 Transfection Deteriorates the ox-LDLInduced Apoptosis in EAhy926 Cells. HCMV has clearly been shown to be associated with vasculopathy and atherosclerosis [25-28]. And the ox-LDL-induced apoptosis via binding to LOX-1 in vascular endothelial cells $[4,6]$ has been well determined. To observe the influence of miR-US25-1 on the ox-LDL promoted endothelial cell apoptosis, we treated the EAhy926 cells with ox-LDL and with miR-US25-1 mimics transfection. Firstly, Figure 4(a) showed that the ox-LDL with 10 or $50 \mu \mathrm{g} / \mathrm{mL}$ reduced the EAhy926 cell viability significantly $(P<0.05$ for $10 \mu \mathrm{g} / \mathrm{mL}$ and for $50 \mu \mathrm{g} / \mathrm{mL}$ at 24 H.P.T.; $P<0.01$ for $50 \mu \mathrm{g} / \mathrm{mL}$ at $48 \mathrm{~h}$ ). Then, the cell apoptosis was examined by flow cytometry. It was shown in Figures 4(b)-4(d) that the treatment with ox-LDL induced significantly increased apoptosis (with a percentage of apoptotic cells of $16.32 \pm 2.14$ at $24 \mathrm{~h}$ after treatment and $37.43 \pm 5.62$ at $48 \mathrm{~h}$ after treatment, either $P<0.05)$. And what is more, the miR-US25-1 mimics transfection (50 nM) accelerated the ox-LDL-induced apoptosis (a percentage of $32.67 \pm 5.31$ versus $16.32 \pm 2.14$ at 24 H.P.T. and a percentage of $35.58 \pm 5.66$ versus $56.55 \pm 8.19$ at 48 H.P.T.; either $P<0.05)$. To further confirm the apoptosis induction by ox-LDL, we quantified by western blot assay the expressions of LOX-1, that is, ox-LDL receptor, cytochrome $\mathrm{C}$ (Cyt $\mathrm{C}$ ) release, and cIAP-1 expression, which were up- or downregulated in the context of ox-LDL-induced apoptosis [6]. It was shown in Figures 5(a) and 5(b) that the ox-LDL induced significantly high level of LOX-1 expression and Cyt $C$ release $(P<0.05$ for LOX-1 at 24 or $48 \mathrm{~h}$ and for Cyt C at 12, 24, or $48 \mathrm{~h}$, resp.). And the caspase 3 activity was also assayed to reconfirm the apoptosis inductivity of ox-LDL. Figure 5(c) indicated that the caspase 3 activity in EAhy926 cells after ox-LDL treatment was elevated for approximately 4 times at 24 H.P.T. or 6 times at 48 H.P.T., with a significance $(P<0.05$ or $P<0.01)$. Thus, the apoptosis induction by ox-LDL was confirmed in EAhy926 cells.

An aggravation to the ox-LDL-induced apoptosis of miR-US25-1 has been confirmed by the flow cytometry for apoptotic cells. To further confirm the aggravation by miRUS25-1 in the molecular level, the regulation of miR-US251 on LOX-1, Cyt C, and cIAP-1 was assayed in both mRNA and protein levels. It was shown that the miR-US25-1 did not downregulate the expression of LOX-1, Cyt C, and cIAP1 in mRNA level (Figures 6(a)-6(c)) before 48 hours after transfection. However, at 48 H.P.T., mRNAs of the three molecules were expressed in a significantly low level in the miR-US25-1-transfected cells than in the control miRNAtransfected cells; particularly, the cIAP-1 mRNA even reduced in cells transfected control microRNA (Figures 6(a)-6(c)). Then, the caspase 3 activity was also assayed to identify the aggravation by miR-US25-1 on the apoptosis inductivity by ox-LDL. Figure 6(d) indicated that the caspase 3 activity in EAhy926 cells after miR-US25-1 transfection was elevated significantly higher than in the cells after control miRNA transfection, either at 24 or 48 H.P.T. ( $P<0.05$ either). Western blot analysis was also conducted to analyze the influence of miR-US25-1 on apoptosis-associated molecules. It was shown that the upregulation by ox-LDL in LOX-1 expression was not significantly influenced by the miR-US251 , compared to the control microRNA group $(P>0.05$ for 24 or 48 H.P.T.). However, the miR-US25-1 aggravated the promotion by ox-LDL on the Cyt $\mathrm{C}$ release (a percentage of $61.50 \pm 7.85$ versus $29.52 \pm 4.26$ at 24 H.P.T. and a percentage of $52.25 \pm 7.33$ versus $24.32 \pm 4.50$ at 48 H.P.T.; either $P<0.05$ ) and c-IAP-1 expression (a percentage of $29.80 \pm 4.23$ versus $19.32 \pm 2.98$ at 24 H.P.T. and a percentage of $44.47 \pm 5.75$ versus $32.85 \pm 4.25$ at 48 H.P.T.; either $P<0.05)$.

\section{Discussion}

Studies have demonstrated that the HCMV genomes, as other members of its Herpesviridae family, encode miRNAs [42, $43,48]$, which were shown to participate in the complex regulation of host cell metabolism and immune evasion [39, $44,49]$. HCMV miRNAs have been demonstrated to be expressed during acute lytic infection [40-43]. miR-US25-1 is one of HCMV-encoded miRNAs and targets cellular genes that are essential for virus growth to control the life cycle of the virus [44]. More recently, it is shown that the viral miR-US25-1 downregulates multiple cell cycle genes through mRNA 5' UTRs [45]. The prominent regulation of cell cycle genes of the miR-US25-1 attracts us to explore its role in the atherosclerosis promotion.

In present study, we confirmed the upregulation of miRUS25-1 level in normal subjects or atherosclerosis patients and in endothelial cells with HCMV infection; there was a significant association of miR-US25-1 level with the active HCMV infection, and the miR-US25-1 expression correlated with the mRNA level of pp65, one of HCMV tegument proteins in the atherosclerosis patients. The in vitro experiment also revealed that HCMV infection promoted miR-US25-1 expression in EAhy926 endothelial cells. Then the regulatory role of miR-US25-1 in EAhy926 cells was determined. It was shown that the miR-US25-1 mimics reduced cell viability but did not induce apoptosis in EAhy926 cells.

It has been reported that the HCMV-encoded miR-US251 primarily binds sites within the $5^{\prime}$ UTR of targeted genes and mediates the reduction in gene expression [45]. And many of the targeted genes are associated with cell cycle control, including cyclin E2 and BRCC3 [45]. To explore the mechanism into the confirmed viability reduction by miR-US25-1, we investigated the association of miR-US25-1 


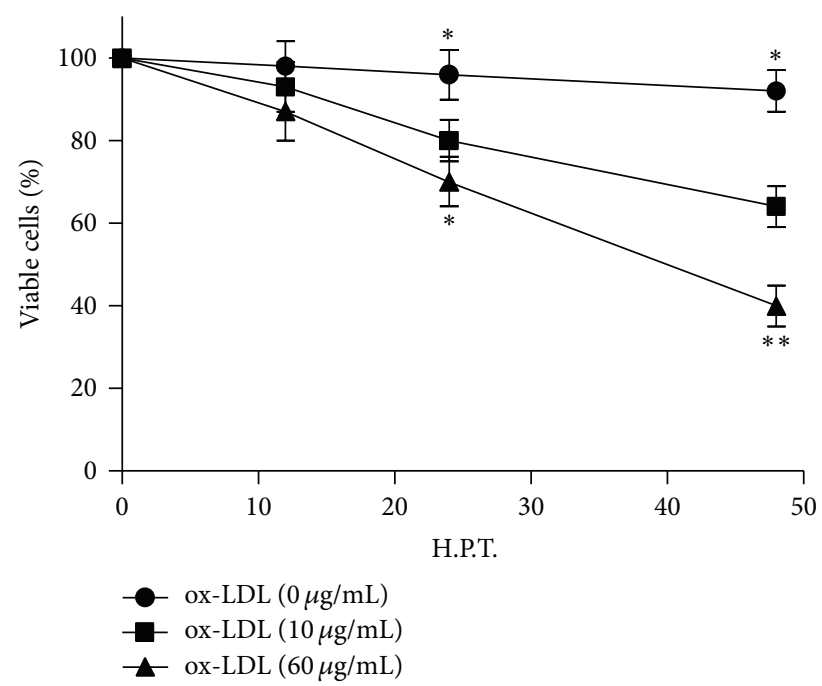

(a)
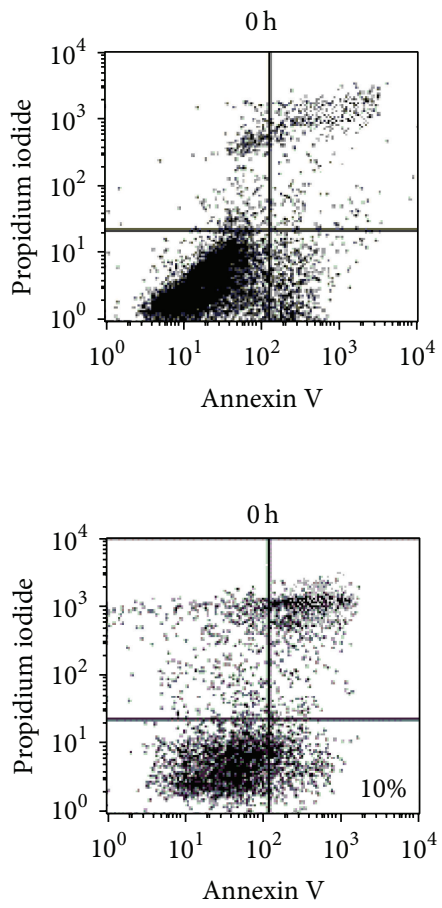

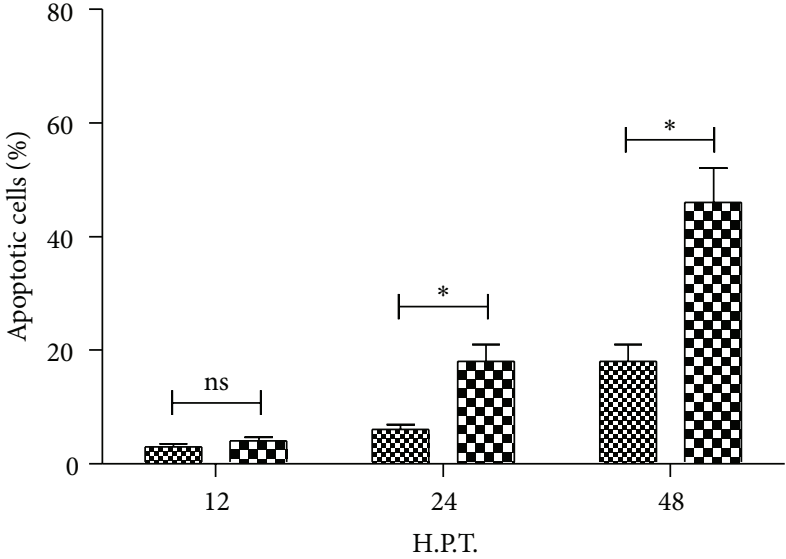

Q⿻x ox-LDL $(0 \mu \mathrm{g} / \mathrm{mL})$

Ex ox-LDL $(60 \mu \mathrm{g} / \mathrm{mL})$

(b)

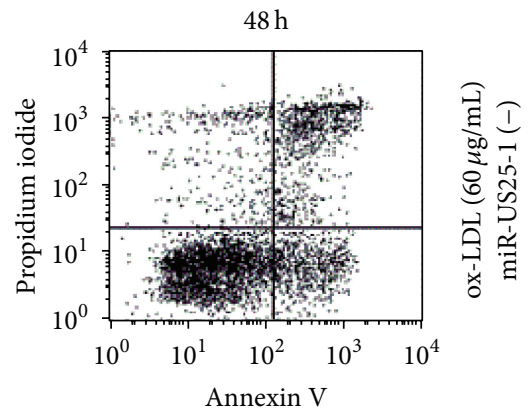

(c)
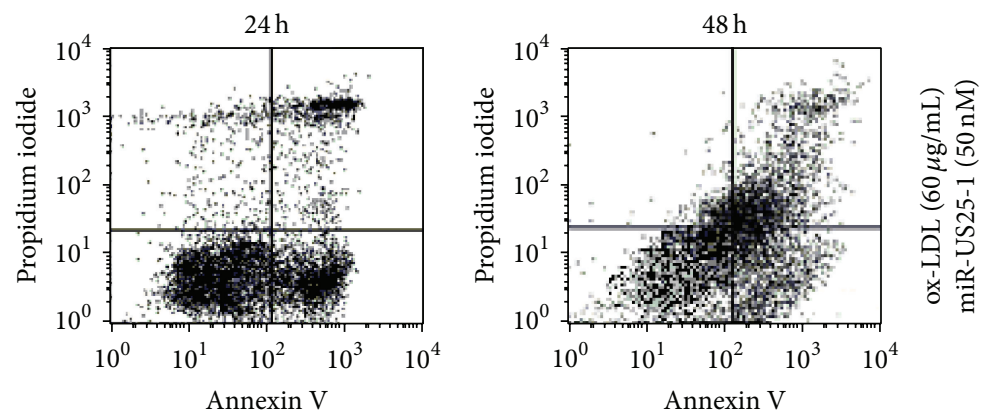

(d)

FIGURE 4: miR-US25-1 aggravates the ox-LDL-induced apoptosis in EAhy926 cells. (a) Viability of EAhy926 cells significantly decreased 24 or $48 \mathrm{~h}$ after treatment with 10 or $50 \mu \mathrm{g} / \mathrm{mL}$ ox-LDL (MTT assay). (b) miR-US25-1 mimics aggravated the apoptosis of EAhy926 cells treated with ox-LDL. (c) Apoptosis in EAhy926 cells after $50 \mu \mathrm{g} / \mathrm{mL}$ ox-LDL treatment and $50 \mathrm{nM}$ miRNA control transfection. (d) Apoptosis of EAhy 926 cells after treatment of $50 \mu \mathrm{g} / \mathrm{mL}$ ox-LDL and $50 \mathrm{nM}$ miR-US25-1 mimics.

with its possible targeted genes, involving cyclin E2, BRCC3, and EID1, and found a significant reduction of BRCC 3 in EAhy926 cells after miR-US25-1 mimics transfection, while no significant results got in cyclin E2 and EID1 mRNA expression (data not shown). Since BRCC 3 is one of most regulated molecules by miR-US25-1, we speculated that the cell viability reduction might be caused by the BRCC 3 blockage. And to further investigate the role of miR-US25-1 in the HCMV-associated atherosclerosis, we then determined the synergy role of miR-US25-1 in the ox-LDL-induced apoptosis in EAhy926 cells, given the vital role of BRCC 3 in DNA damage repairing [47].

Firstly, we confirmed that the ox-LDL reduced the viability of EAhy926 cells significantly via inducing cell apoptosis (flow cytometry with annexin V/PI double staining). The western blot results reconfirmed the on-LDL-promoted apoptosis, revealing by the upregulation of LOX-1 expression and cytochrome $\mathrm{C}$ (Cyt $\mathrm{C}$ ) release the downregulation of 


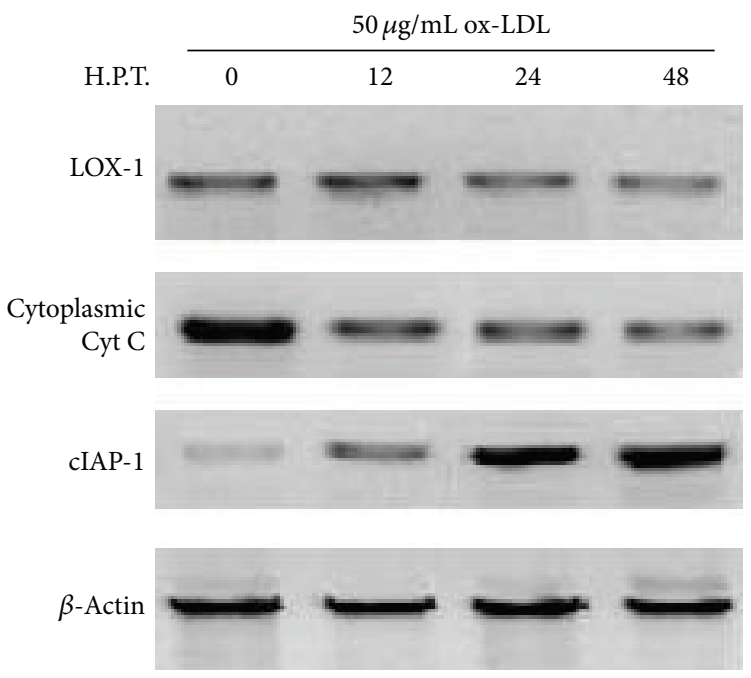

(a)
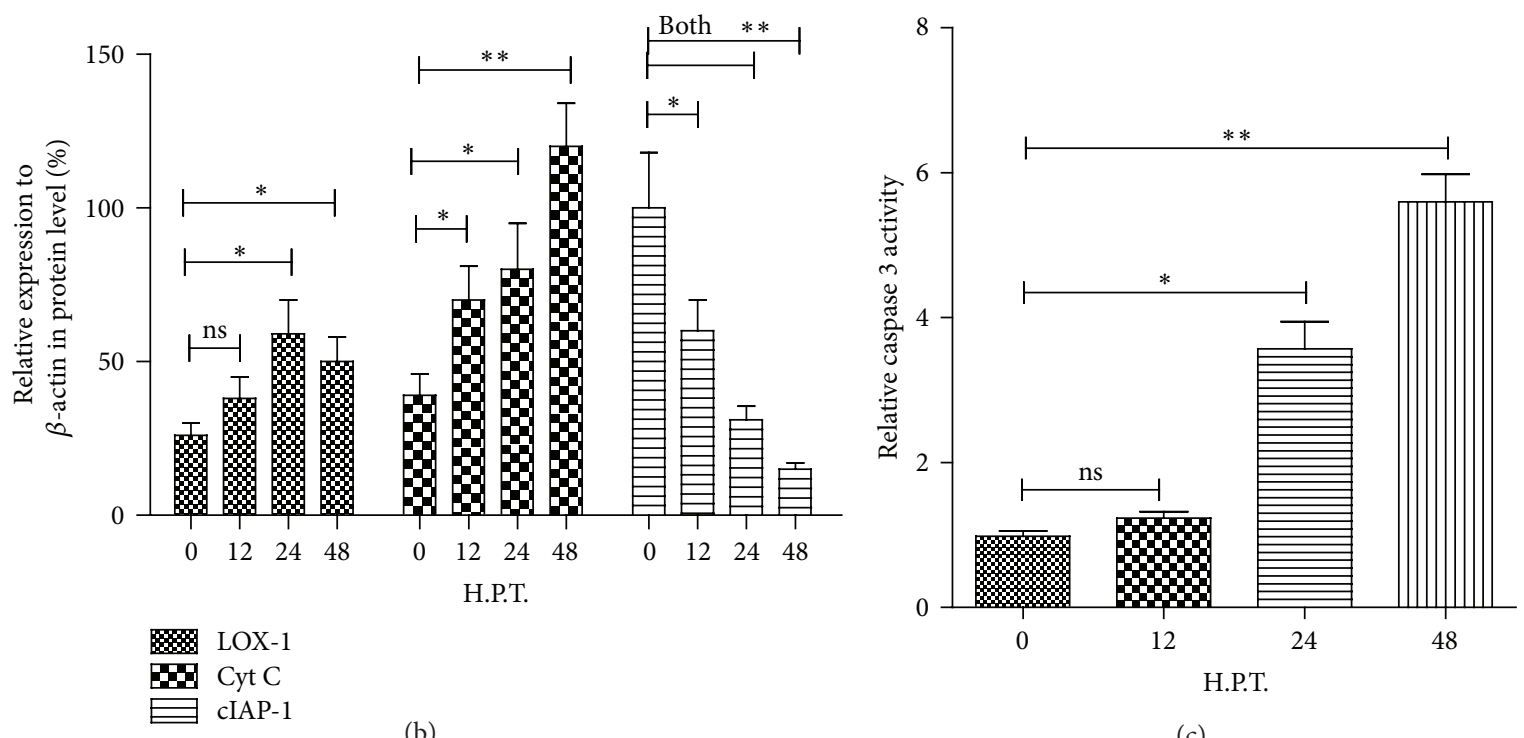

(b)

(c)

FIGURE 5: Deregulation of ox-LDL receptor and apoptosis-associated molecules in EAhy926 cells by ox-LDL treatment. (a) and (b) ox-LDL significantly promoted the expression of LOX-1, the ox-LDL receptor on EAhy926 cells, and the release of Cyt c and downregulated cIAP-1 expression, an apoptosis inhibiting protein. Western blot assay was conducted to identify the protein level of the three molecules, compared to $\beta$-actin. (c) Significant upregulation of caspase 3 activity in EAhy926 cells after treatment of $50 \mu \mathrm{g} / \mathrm{mL}$ ox-LDL. All results were got from triplicate independent experiments. Statistical significance was showed as ${ }^{*} P<0.05$ and ${ }^{* *} P<0.01$, ns: no significance.

cIAP-1 expression in the context of ox-LDL-induced apoptosis [6]. And the caspase 3 activity was also significantly promoted by ox-LDL. Thus, the apoptosis induction by oxLDL was confirmed in EAhy926 cells. And what is more, the miR-US25-1 mimics transfection accelerated the ox-LDLinduced apoptosis by both flow cytometry assay and western blot analysis of apoptosis-associated molecules.

Life-long persistent HCMV infection is linked to the development and severity of the cardiovascular disease atherosclerosis [24], with a serological confirmation [27, 28]. And in vivo studies have revealed that HCMV infection of the vessel wall affects various cells including monocytes/macrophages, smooth muscle cells (SMCs), and endothelial cells (ECs) leading to the dysfunction of ECs and the activation of proinflammatory signaling [30], which promotes enhanced proliferation, migration of monocytes and SMCs into the intima of the vascular wall, and expansion of atherosclerotic lesion $[50,51]$. An enhanced expression of 


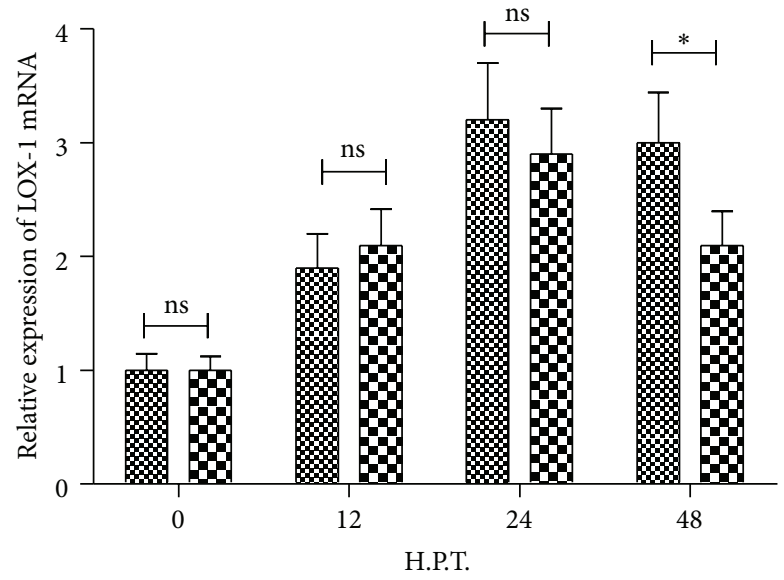

$\$$ miR con.

10 miR-US25-1

(a)

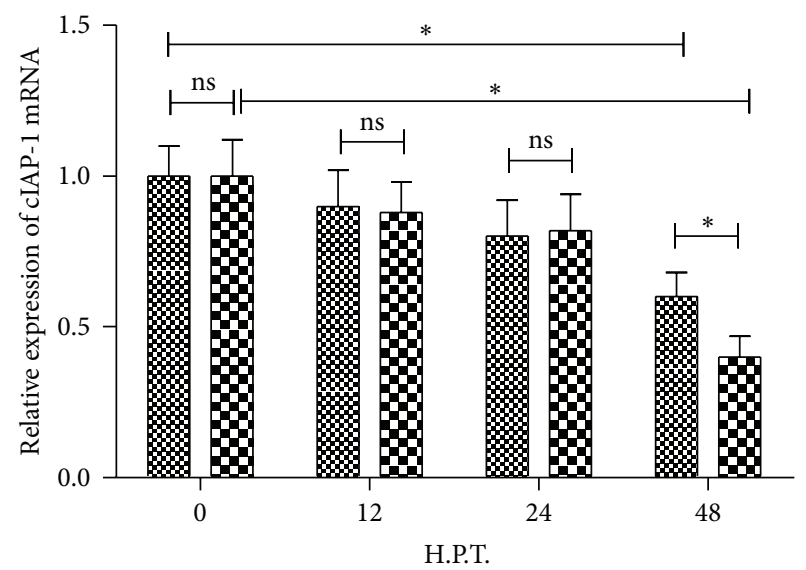

\% miR con.

E miR-US25-1

(c)

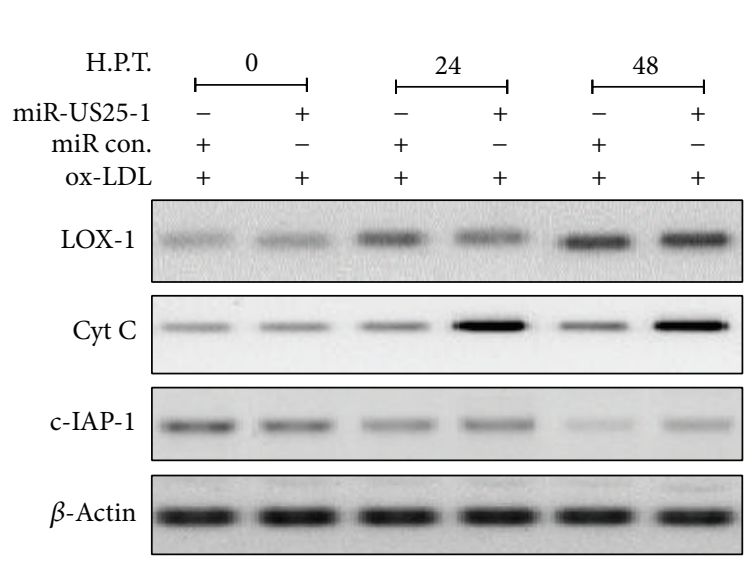

(e)

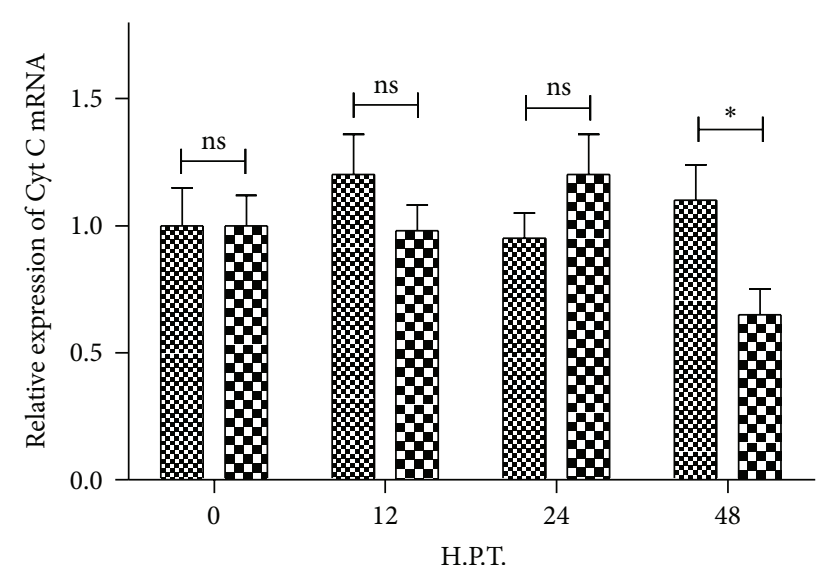

$\geqslant$ miR con.

miR-US25-1

(b)

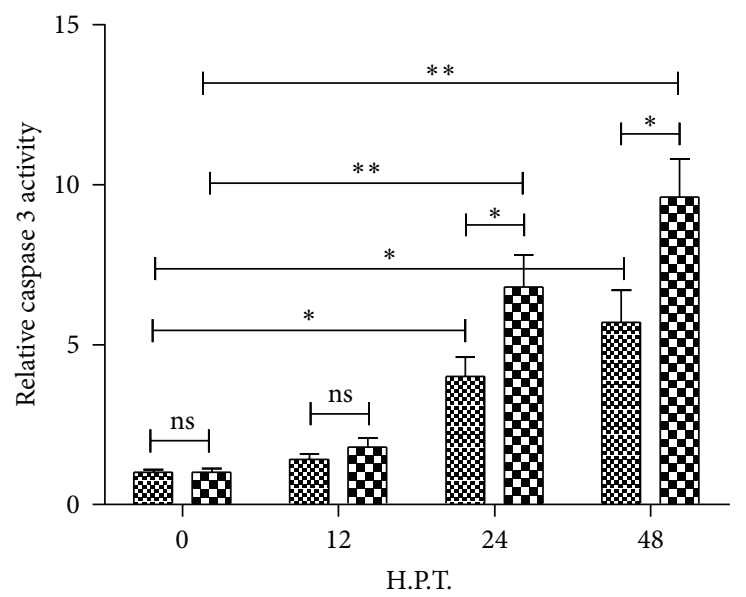

\% miR con.

miR-US25-1

(d)

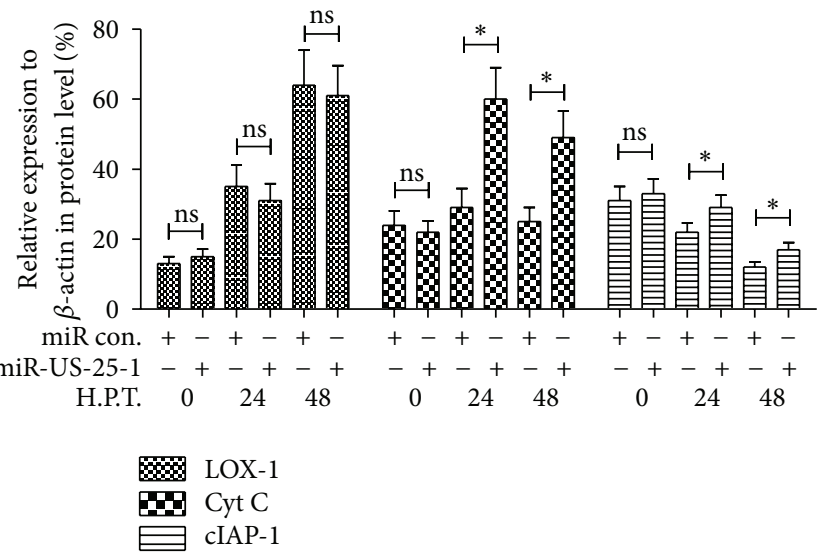

(f)

FIGURE 6: miR-US25-1 aggravated the deregulation of ox-LDL on the expression of LOX and cIAP-1 and the release of Cyt c in EAhy926 cells. (a)-(c) Influence of miR-US25-1 mimics transfection (50 nM) on the expression of LOX, cIAP-1, and Cyt c in mRNA levels in EAhy926 cells after $50 \mu \mathrm{g} / \mathrm{mL}$ ox-LDL treatment. (d) miR-US25-1 mimics transfection ( $50 \mathrm{nM}$ ) deteriorated the upregulation of the caspase 3 activity in EAhy 926 cells by treatment of $50 \mu \mathrm{g} / \mathrm{mL}$ ox-LDL. (e) and (f) Western blot assay of LOX expression, cIAP-1 expression, and Cyt c release in EAhy 926 cells which were treated with $50 \mu \mathrm{g} / \mathrm{mL}$ ox-LDL and transfected with $50 \mathrm{nM}$ miR-US25-1 mimics or $50 \mathrm{nM}$ miRNA control $(\beta$-actin as control). All results were got from triplicate independent experiments. Statistical significance was showed as ${ }^{*} P<0.05$ and ${ }^{* *} P<0.01$, ns: no significance. 
endothelial adhesion molecules has also been promoted by HCMV infection [30], as a consequence of which infected endothelium recruits naive monocytes in the infected sites. Endothelial damage by HCMV infection may also promote thrombin generation linking inflammation and coagulation [52]. However, there is little direct evidence of the association of HCMV with the atherosclerosis. Present study indicated that the HCMV-encoded microRNA and miR-US25-1 aggravated the ox-LDL-induced apoptosis of endothelial cells via targeting and downregulating BRCC 3; the synergy role of it in ox-LDL-induced apoptosis might contribute to the association of HCMV with atherosclerosis.

miR-US25-1 was reported to primarily bind sites within the $5^{\prime}$ UTR of targeted genes and mediate the reduction in gene expression [45]. And many of the genes targeted by miR-US25-1 are associated with cell cycle control, including cyclin E2 and BRCC3 [45]. In the present study, we have also confirmed the deregulation of BRCC 3 expression by miRUS25-1 and targeting the $5^{\prime}$ UTR of BRCC 3. Given the vital role of BRCC 3 in DNA damage repairing [47], we speculated that the targeting inhibition of BRCC 3 by miR-US25-1 may contribute to the cell viability reduction and the aggravation to ox-LDL-promoted apoptosis of endothelial EAhy926 cells.

\section{Material and Methods}

4.1. Subjects. A group of 28 subjects with HCMV infection and 10 subjects without HCMV infection were recruited in this study from the outpatients of the Second Xiangya Hospital of Central South University. All atherosclerosis patients with (32 cases) or without (15 cases) HCMV infection were selected from the outpatients or inpatients registered in Cardiovascular Medicine Department, the Second Xiangya Hospital of Central South University. Informed consent was obtained from all subjects, and the study was approved by the Ethics Committee of Central South University.

4.2. Cell Cultures, Virus, and Reagents. The human embryo fibroblast cells (HEF cells) were utilized for HCMV isolation and growth determination, and the human umbilical vein cell line, EAhy926 cells were utilized for HCMV growth curve assay. HEF cells and EAhy926 cells were provided by the Central Laboratory, Central South University, and cultured in DMEM or RPMI 1640 medium (Invitrogen, Carlsbad, CA, USA) supplemented with 10\% FBS (Gibco, Rockville, MD, USA) at $37^{\circ} \mathrm{C}$ under $5 \% \mathrm{CO}_{2}$. The DMEM or RPMI 1640 medium supplemented with 2\% FBS was used for the HEF cells or EAhy 926 cells maintaining postgrowing to about $90 \%$ confluence.

HCMV strain, AD169, was used to determine the virus growth curve and miR-US25-1 promotion with 0.1 or $1 \mathrm{MOI}$ of AD169. ox-LDL (Cat.\# BT-910) was purchased from Biomedical Technologies Inc. (Stoughton, MA, USA) and resolved in the RPMI 1640 medium supplemented with 2\% FBS. ox-LDL with a concentration of $50 \mu \mathrm{g} / \mathrm{mL}$ was used for EAhy 926 cell treatment. The miR-US25-1 mimics (GenePharma, Shanghai, China) were utilized to manipulate the miR-US25-1 level in EAhy926 cells. $50 \mathrm{nM}$ miRNA mimics or miRNA control (scramble-control miRNA) (GenePharma, Shanghai, China) was transfected with Lipofectamine 2000. To identify the influence of miR-US25-1 on the cell viability or apoptosis, the EAhy926 cells after miR-US25-1 mimics or miRNA control transfection for various hours or days was maintained, with or without ox-LDL treatment.

4.3. RNA Isolation, Reverse Transcription, and qPCR. Total cellular RNA was purified with PureLink RNA Mini Kit (Invitrogen, Carlsbad, CA, USA), and miRNAs were isolated using mirVana miRNA Isolation Kit (Ambion, Austin, TX, USA) according to the kit manuals. The quantitative reverse transcription-PCR (RT-PCR) was performed with Takara One Step RT-PCT kit (Takara, Dalian, China). For quantitative analysis of mRNA expression of pp65 of HCMV, LOX1, Cyt c, and c-IAP-1, the mRNA samples were amplified using primer/probe sets specific for the genes of interest on a Lightcycler 480 II (Roche, Mannheim, Germany). Relative quantification was determined using the $\Delta \Delta \mathrm{Ct}$ method using $\beta$-actin as reference gene [53]. The primers used were available upon request.

4.4. Plaque Forming Assay and Growth Curve. Cell-free HCMV virus stocks (AD169) were serially 10 -fold diluted in DMEM medium with 2\% FBS and inoculated HEF monolayer cells for 2 hours; then the cell layers were washed with warm PBS twice and overlaid with $1 \%$ methylcellulose. After incubation for 7 to 10 days, the cultures were fixed and plaques were stained with $0.5 \%$ crystal violet. PFU per milliliter counted. HEF or EAhy926 cells were cultured in growth plate with 12 holes to $90 \%$ confluence and were inoculated with 0.1 MOI AD169 virus for 2 hours. Cells were replaced with new medium and incubated for various time, after three-time washing with PBS. Then the cell supernatant was collected and titered by plaque forming assay.

4.5. Cell Viability and Apoptosis Assays. Cell viability was evaluated by methyl thiazolyl tetrazolium assay (MTT assay) (Invitrogen, Carlsbad, CA, USA). EAhy926 cells after (both) ox-LDL treatment or (and) miR-US25-1 transfection were incubated with $50 \mu \mathrm{L}$ MTT solution at $37^{\circ} \mathrm{C}$ for another $2 \mathrm{~h}$ and were dissolved by $150 \mu \mathrm{L}$ DMSO completely at room temperature. The absorbance was then measured at $570 \mathrm{~nm}$ using a spectrophotometer (Bio-Rad, Hercules, CA, USA). Cell apoptosis was determined by an annexin VFITC apoptosis detection kit (Sigma-Aldrich, St. Louis, MO, USA). Briefly, $1-5 \times 10^{5}$ cells after ox-LDL treatment or (and) miR-US25-1 transfection were collected and resuspended in $0.5 \mathrm{~mL}$ of binding buffer and incubated with annexin V-FITC and propidium iodide for $10 \mathrm{~min}$ in the dark at room temperature and then assayed with an FACScan flow cytometer (Bio-Rad, Hercules, CA, USA) equipped with a FITC signal detector FL1 (excitation $488 \mathrm{~nm}$, green) and a phycoerythrin emission signal detector FL3 (excitation $585 \mathrm{~nm}$, red). Results were calculated using the CellQuest Pro software (BD Biosciences) and expressed as the percentage of apoptotic (including early and late apoptotic cells) to total cells. Caspase 3 activity was determined using the Enzchek 
Caspase-3 Assay Kit \#2 (Invitrogen). Cell extracts were incubated with the caspase substrate Z-DEVD-R110 (25 mM, final concentration) for $3.5 \mathrm{~h}$ in the dark, at room temperature. The appearance of fluorescent rhodamine 110 (R-110) upon enzymatic cleavage of the nonfluorescent substrate Z-DEVDR110 was subsequently assayed using a microplate reader (Ex: $485 \mathrm{~nm}$; Em: $520 \mathrm{~nm}$ ). Negative controls (samples without the Z-DEVD-R110 substrate) and substrate-only controls (mixture of activity buffer and Z-DEVD-R110 substrate to determine the background fluorescence of the substrate) were also carried out. The results were expressed as a relative value to the caspase 3 activity of pretreated cells.

4.6. Immunoblotting. Cells (approximately $10^{5}$ ) were lysed with the Cytoplasmic, Mitochondria, Membrane, and Nuclear Protein Extraction Kit (ZmTech Scientific Inc., San Jose, CA, USA) and supplemented with Complete Mini Protease Inhibitor Cocktail (Roche, Basel, Switzerland) according to manuals. After protein concentration determination using Bradford Reagent (Bio-Rad, Hercules, CA, USA), the protein samples were separated by a $12 \%$ gradient SDS-PAGE gel, transferred to PVDF membrane, and blocked in 5\% skimmed milk. The following primary antibodies were utilized: BRCC 3 rabbit polyclonal antibody, 1:300 (Santa Cruz Biotech), LOX-1 rabbit polyclonal antibody, 1:300 (Sino Biological, Beijing, China), Cyt c rabbit polyclonal antibody, 1:500 (Sigma-Aldrich, St. Louis, MO, USA), c-IAP-1 rabbit polyclonal, 1:500 (Santa Cruz Biotechnology, Santa Cruz, CA, USA), or $\beta$-actin rabbit polyclonal, $1: 1000$ (Sigma-Aldrich, St. Louis, MO, USA). Goat anti-rabbit IgG conjugated to horseradish peroxidase (Pierce, Rockford, IL, USA) and ECL detection systems (Super Signal West Femto; Pierce, Rockford, IL, USA) were used for detection.

4.7. Luciferase Activity Assay. Reporter plasmid with BRCC 3 or BRCC 3 mut $5^{\prime}$ UTR (pGL3) was constructed by our lab; the pGL3 with the $5^{\prime}$ UTR of BRCC 3 was inserted with the miR-US25-1 targeting sequence in BRCC 3 (UGGCGGU) with three repeated copies, at the multiple cloning sites before luciferase coding sequence. While the inserted sequence in the pGL3 with the mutated $5^{\prime}$ UTR of BRCC 3 was mutated to cGaataac $1 \times 10^{5}$, EAhy 926 cells were transfected with $50 \mathrm{nM}$ of miRNA control or miR-US25-1 mimics and $0.5 \mu \mathrm{g}$ reporter plasmid with Lipofectamine 2000. $6 \mathrm{~h}$ after transfection, cells were inoculated with RPMI 1640 containing 10\% FBS for another $24 \mathrm{~h}$ and harvested for analysis. Luciferase activity was determined with a Promega Luciferase Assay System (Madison, WI, USA).

\section{Conflict of Interests}

The authors declare that there is no conflict of interests regarding the publication of this paper.

\section{Acknowledgment}

This study was supported by the Grant from The Second Xiangya Hospital of Central South University.

\section{References}

[1] S. Ehara, M. Ueda, T. Naruko et al., "Elevated levels of oxidized low density lipoprotein show a positive relationship with the severity of acute coronary syndromes," Circulation, vol. 103, no. 15, pp. 1955-1960, 2001.

[2] T. Kita, N. Kume, M. Minami et al., "Role of oxidized LDL in atherosclerosis," Annals of the New York Academy of Sciences, vol. 947, pp. 199-206, 2001.

[3] D. Li and J. L. Mehta, "Antisense to LOX-1 inhibits oxidized LDL-mediated upregulation of monocyte chemoattractant protein-1 and monocyte adhesion to human coronary artery endothelial cells," Circulation, vol. 101, no. 25, pp. 28892895, 2000.

[4] D. Li and J. L. Mehta, "Upregulation of endothelial receptor for oxidized LDL (LOX-1) by oxidized LDL and implications in apoptosis of coronary artery endothelial cells: evidence from use of antisense LOX-1 mRNA and chemical inhibitors," Arteriosclerosis, Thrombosis, and Vascular Biology, vol. 20, no. 4, pp. 1116-1122, 2000.

[5] L. Cominacini, A. Fratta Pasini, U. Garbin et al., "Oxidized low density lipoprotein (ox-LDL) binding to ox-LDL receptor-1 in endothelial cells induces the activation of NF- $\kappa$ B through an increased production of intracellular reactive oxygen species," Journal of Biological Chemistry, vol. 275, no. 17, pp. 12633-12638, 2000.

[6] J. Chen, J. L. Mehta, N. Haider, X. Zhang, J. Narula, and D. $\mathrm{Li}$, "Role of caspases in Ox-LDL-induced apoptotic cascade in human coronary artery endothelial cells," Circulation Research, vol. 94, no. 3, pp. 370-376, 2004.

[7] W. Zhang, D. Li, and J. L. Mehta, "Role of AIF in human coronary artery endothelial cell apoptosis," American Journal of Physiology: Heart and Circulatory Physiology, vol. 286, no. 1, pp. H354-H358, 2004.

[8] Y.-P. Bai, C.-P. Hu, Q. Yuan et al., "Role of VPO1, a newly identified heme-containing peroxidase, in ox-LDL induced endothelial cell apoptosis," Free Radical Biology and Medicine, vol. 51, no. 8, pp. 1492-1500, 2011.

[9] L. I. Dayuan, B. Yang, and J. L. Mehta, "Ox-LDL induces apoptosis in human coronary artery endothelial cells: role of PKC, PTK, bcl-2, and Fas," American Journal of Physiology, vol. 275, no. 2, pp. H568-H576, 1998.

[10] S. Mitra, M. Khaidakov, J. Lu et al., "Prior exposure to oxidized low-density lipoprotein limits apoptosis in subsequent generations of endothelial cells by altering promoter methylation," American Journal of Physiology: Heart and Circulatory Physiology, vol. 301, no. 2, pp. H506-H513, 2011.

[11] M. Roivainen, M. Viik-Kajander, T. Palosuo et al., "Infections, inflammation, and the risk of coronary heart disease," Circulation, vol. 101, no. 3, pp. 252-257, 2000.

[12] P. M. Ridker, M. Cushman, M. J. Stampfer, R. P. Tracy, and C. H. Hennekens, "Inflammation, aspirin, and the risk of cardiovascular disease in apparently healthy men," New England Journal of Medicine, vol. 336, no. 14, pp. 973-979, 1997.

[13] E. Lalla, I. B. Lamster, M. A. Hofmann et al., "Oral infection with a periodontal pathogen accelerates early atherosclerosis in apolipoprotein E-null mice," Arteriosclerosis, Thrombosis, and Vascular Biology, vol. 23, no. 8, pp. 1405-1411, 2003.

[14] S. Kiechl, G. Egger, M. Mayr et al., "Chronic infections and the risk of carotid atherosclerosis: prospective results from a large population study," Circulation, vol. 103, no. 8, pp. 1064-1070, 2001. 
[15] S. E. Epstein, Y. F. Zhou, and J. Zhu, "Infection and atherosclerosis: emerging mechanistic paradigms," Circulation, vol. 100, no. 4, pp. e20-28, 1999.

[16] P. Libby, P. M. Ridker, and A. Maseri, "Inflammation and atherosclerosis," Circulation, vol. 105, no. 9, pp. 1135-1143, 2002.

[17] D. N. Streblow, S. L. Orloff, and J. A. Nelson, "Do pathogens accelerate atherosclerosis?” Journal of Nutrition, vol. 131, no. 10, pp. 2798S-2804S, 2001.

[18] C. Söderberg-Nauclér, "Does cytomegalovirus play a causative role in the development of various inflammatory diseases and cancer?" Journal of Internal Medicine, vol. 259, no. 3, pp. 219246, 2006.

[19] J. Fan, T. Shimokama, S. Haraoka, O. Tokunaga, and T. Watanabe, "Monocyte-endothelial cell interactions in vitro, with reference to the influence of interleukin-1 and tumor necrosis factor," Biology of the Cell, vol. 79, no. 1, pp. 17-26, 1993.

[20] P. Libby, G. B. Friedman, and R. N. Salomon, "Cytokines as modulators of cell proliferation in fibrotic diseases," American Review of Respiratory Disease, vol. 140, no. 4, pp. 1114-1117, 1989.

[21] J. Plutzky, "Inflammatory pathways in atherosclerosis and acute coronary syndromes," American Journal of Cardiology, vol. 88, no. 8, supplement 1, pp. 10-15, 2001.

[22] C. M. Dollery, J. R. McEwan, and A. M. Henney, "Matrix metalloproteinases and cardiovascular disease," Circulation Research, vol. 77, no. 5, pp. 863-868, 1995.

[23] H. R. Lijnen and D. Collen, "Matrix metalloproteinase system deficiencies and matrix degradation," Thrombosis and Haemostasis, vol. 82, no. 2, pp. 837-845, 1999.

[24] G. L. Bentz and A. D. Yurochko, "Human CMV infection of endothelial cells induces an angiogenic response through viral binding to EGF receptor and $\beta 1$ and $\beta 3$ integrins," Proceedings of the National Academy of Sciences of the United States of America, vol. 105, no. 14, pp. 5531-5536, 2008.

[25] E. Speir, R. Modali, E.-S. Huang et al., "Potential role of human cytomegalovirus and p53 interaction in coronary restenosis," Science, vol. 265, no. 5170, pp. 391-394, 1994.

[26] P. K. Koskinen, M. S. Nieminen, L. A. Krogerus et al., "Cytomegalovirus infection accelerates cardiac allograft vasculopathy: correlation between angiographic and endomyocardial biopsy findings in heart transplant patients," Transplant International, vol. 6, no. 6, pp. 341-347, 1993.

[27] F. J. Nieto, E. Adam, P. Sorlie et al., "Cohort study of cytomegalovirus infection as a risk factor for carotid intimalmedial thickening, a measure of subclinical atherosclerosis," Circulation, vol. 94, no. 5, pp. 922-927, 1996.

[28] M. Smieja, J. Gnarpe, E. Lonn et al., "Multiple infections and subsequent cardiovascular events in the Heart Outcomes Prevention Evaluation (HOPE) study," Circulation, vol. 107, no. 2, pp. 251-257, 2003.

[29] H. Zhu, J.-P. Cong, G. Mamtora, T. Gingeras, and T. Shenk, "Cellular gene expression altered by human cytomegalovirus: global monitoring with oligonucleotide arrays," Proceedings of the National Academy of Sciences of the United States of America, vol. 95, no. 24, pp. 14470-14475, 1998.

[30] T. J. Dengler, M. J. Raftery, M. Werle, R. Zimmermann, and G. Schönrich, "Cytomegalovirus infection of vascular cells induces expression of pro-inflammatory adhesion molecules by paracrine action of secreted interleukin-1 $\beta$,' Transplantation, vol. 69, no. 6, pp. 1160-1168, 2000.

[31] Y. F. Zhou, Z.X. Yu, C. Wanishsawad, M. Shou, and S. E. Epstein, "The immediate early gene products of human cytomegalovirus increase vascular smooth muscle cell migration, proliferation, and expression of PDGF $\beta$-receptor," Biochemical and Biophysical Research Communications, vol. 256, no. 3, pp. 608-613, 1999.

[32] A. M. Denli, B. B. J. Tops, R. H. A. Plasterk, R. F. Ketting, and G. J. Hannon, "Processing of primary microRNAs by the Microprocessor complex,” Nature, vol. 432, no. 7014, pp. 231235, 2004.

[33] D. P. Bartel, "MicroRNAs: target recognition and regulatory functions," Cell, vol. 136, no. 2, pp. 215-233, 2009.

[34] J. Brennecke, D. R. Hipfner, A. Stark, R. B. Russell, and S. M. Cohen, "bantam encodes a developmentally regulated microRNA that controls cell proliferation and regulates the proapoptotic gene hid in Drosophila," Cell, vol. 113, no. 1, pp. 25-36, 2003.

[35] B. J. Reinhart, F. J. Slack, M. Basson et al., "The 21-nucleotide let-7 RNA regulates developmental timing in Caenorhabditis elegans," Nature, vol. 403, no. 6772, pp. 901-906, 2000.

[36] E. van Rooij, L. B. Sutherland, N. Liu et al., "A signature pattern of stress-responsive microRNAs that can evoke cardiac hypertrophy and heart failure," Proceedings of the National Academy of Sciences of the United States of America, vol. 103, no. 48, pp. 18255-18260, 2006.

[37] M. V. G. Latronico, D. Catalucci, and G. Condorelli, "MicroRNA and cardiac pathologies," Physiological Genomics, vol. 34, no. 3, pp. 239-242, 2008.

[38] K. R. Cordes and D. Srivastava, "MicroRNA regulation of cardiovascular development," Circulation Research, vol. 104, no. 6, pp. 724-732, 2009.

[39] F. Grey, L. Hook, and J. Nelson, “The functions of herpesvirusencoded microRNAs," Medical Microbiology and Immunology, vol. 197, no. 2, pp. 261-267, 2008.

[40] A. H. Buck, J. Santoyo-Lopez, K. A. Robertson, D. S. Kumar, M. Reczko, and P. Ghazal, "Discrete clusters of virus-encoded microRNAs are associated with complementary strands of the genome and the 7.2-kilobase stable intron in murine cytomegalovirus," Journal of Virology, vol. 81, no. 24, pp. 1376113770, 2007.

[41] L. Dölken, J. Perot, V. Cognat et al., "Mouse cytomegalovirus microRNAs dominate the cellular small RNA profile during lytic infection and show features of posttranscriptional regulation," Journal of Virology, vol. 81, no. 24, pp. 13771-13782, 2007.

[42] W. Dunn, P. Trang, Q. Zhong, E. Yang, C. van Belle, and F. Liu, "Human cytomegalovirus expresses novel microRNAs during productive viral infection," Cellular Microbiology, vol. 7, no. 11, pp. 1684-1695, 2005.

[43] S. Pfeffer, A. Sewer, M. Lagos-Quintana et al., "Identification of microRNAs of the herpesvirus family," Nature Methods, vol. 2, no. 4, pp. 269-276, 2005.

[44] N. Stern-Ginossar, N. Saleh, M. D. Goldberg, M. Prichard, D. G. Wolf, and O. Mandelboim, "Analysis of human cytomegalovirus-encoded microRNA activity during infection," Journal of Virology, vol. 83, no. 20, pp. 10684-10693, 2009.

[45] F. Grey, R. Tirabassi, H. Meyers et al., "A viral microRNA downregulates multiple cell cycle genes through mRNA 5'UTRs," PLoS Pathogens, vol. 6, no. 6, Article ID e1000967, 2010.

[46] D. A. Brow and C. Guthrie, "Spliceosomal RNA U6 is remarkably conserved from yeast to mammals," Nature, vol. 334, no. 6179, pp. 213-218, 1988.

[47] Y. Dong, M.-A. Hakimi, X. Chen et al., "Regulation of BRCC, a holoenzyme complex containing BRCA1 and BRCA2, by 
a signalosome-like subunit and its role in DNA repair," Molecular Cell, vol. 12, no. 5, pp. 1087-1099, 2003.

[48] F. Grey, A. Antoniewicz, E. Allen et al., "Identification and characterization of human cytomegalovirus-encoded microRNAs," Journal of Virology, vol. 79, no. 18, pp. 12095-12099, 2005.

[49] F. Grey, H. Meyers, E. A. White, D. H. Spector, and J. Nelson, "A human cytomegalovirus-encoded microRNA regulates expression of multiple viral genes involved in replication," PLoS Pathogens, vol. 3, no. 11, article e163, 2007.

[50] G. Gerna, E. Percivalle, F. Baldanti et al., "Human cytomegalovirus replicates abortively in polymorphonuclear leukocytes after transfer from infected endothelial cells via transient microfusion events," Journal of Virology, vol. 74, no. 12, pp. 5629-5638, 2000.

[51] A. Rahbar and C. Söderberg-Nauclér, "Human cytomegalovirus infection of endothelial cells triggers platelet adhesion and aggregation," Journal of Virology, vol. 79, no. 4, pp. 2211-2220, 2005.

[52] E. L. G. Pryzdial and J. F. Wright, "Prothrombinase assembly on an enveloped virus: evidence that the cytomegalovirus surface contains procoagulant phospholipid," Blood, vol. 84, no. 11, pp. 3749-3757, 1994.

[53] K. J. Livak and T. D. Schmittgen, "Analysis of relative gene expression data using real-time quantitative PCR and the 2$\Delta \Delta$ CT method," Methods, vol. 25, no. 4, pp. 402-408, 2001. 


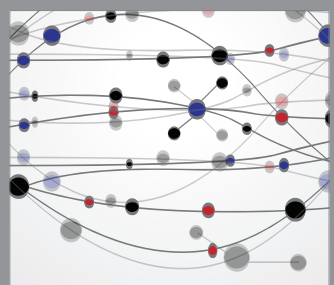

The Scientific World Journal
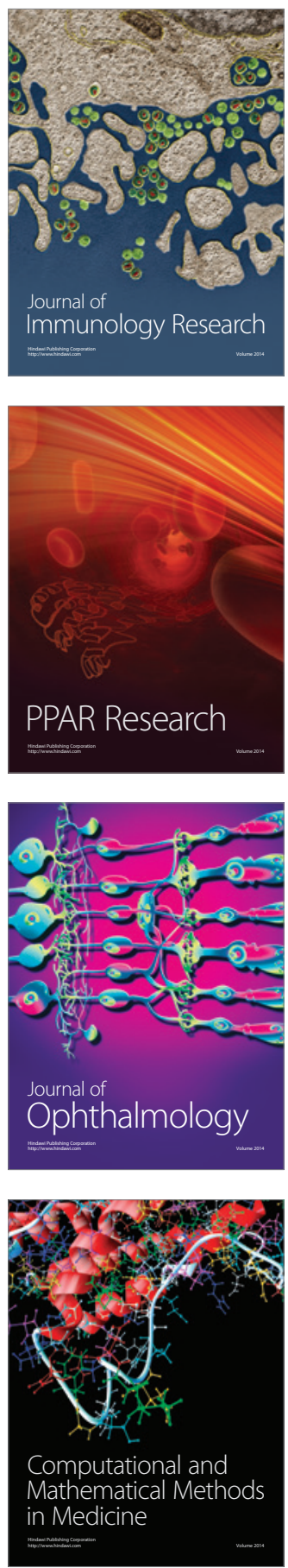

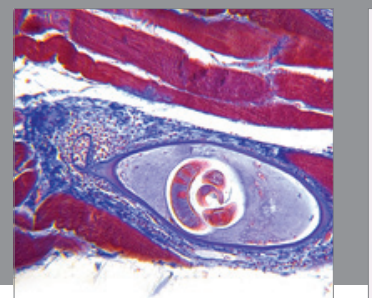

Gastroenterology

Research and Practice
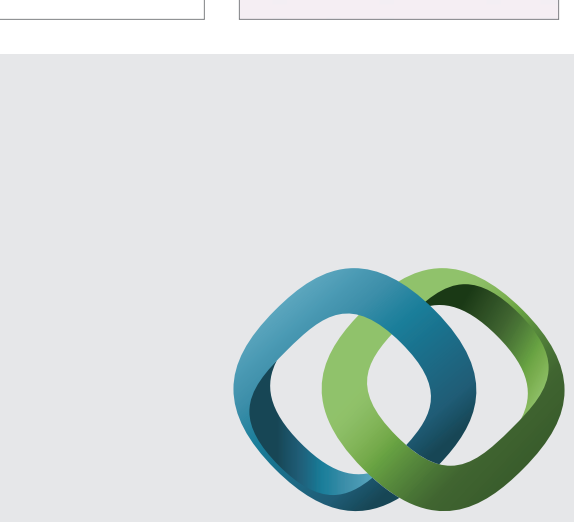

\section{Hindawi}

Submit your manuscripts at

http://www.hindawi.com
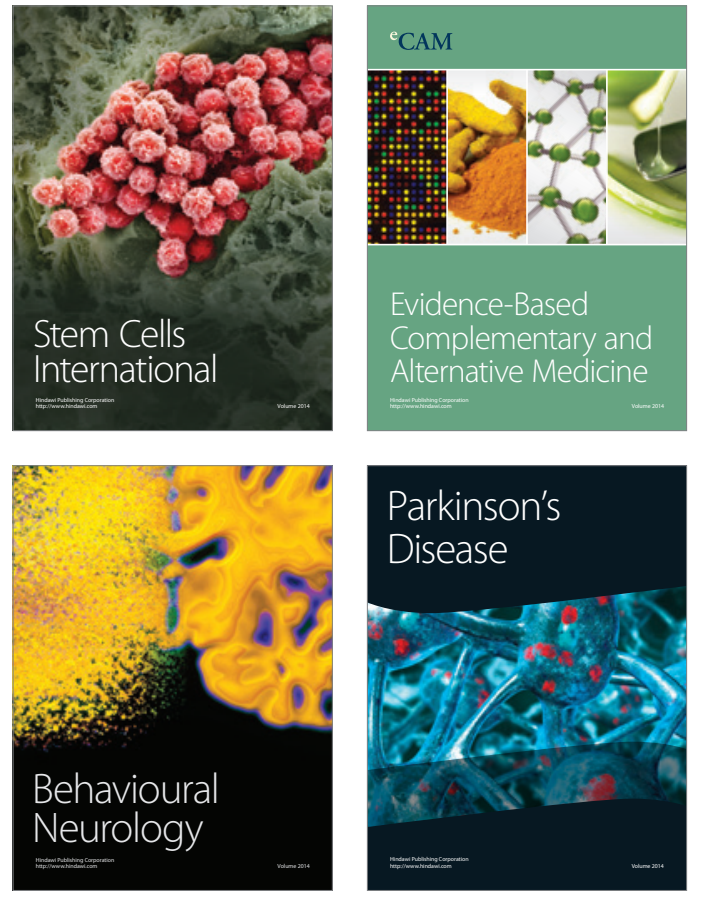
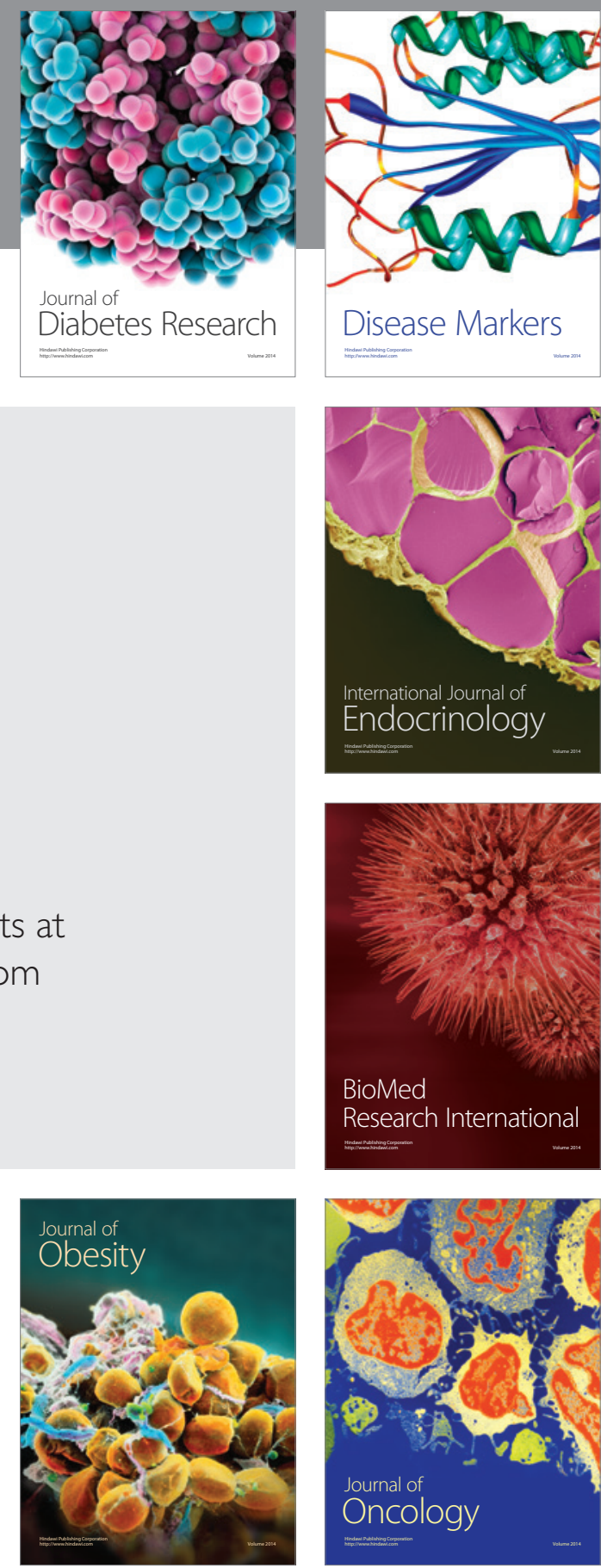

Disease Markers
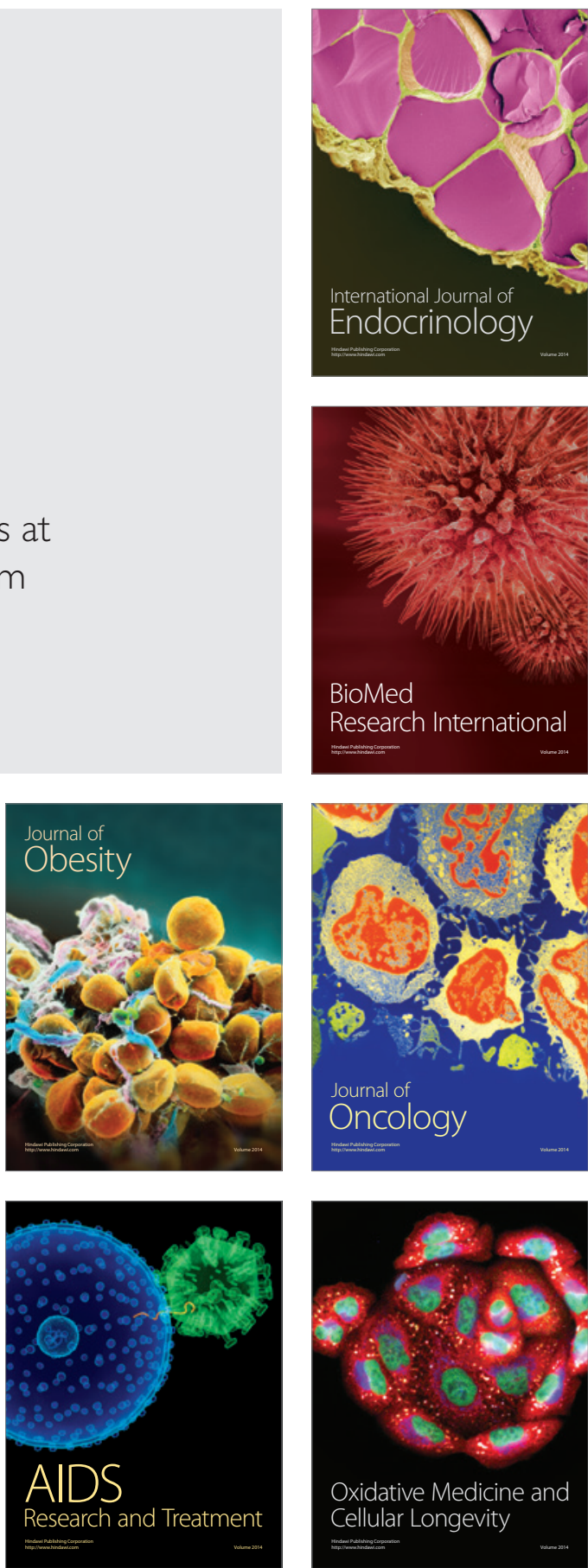